\title{
Perspectives on Current and Novel Treatments for Inflammatory Bowel Disease
}

\author{
Soo-Young $\mathrm{Na}^{1}$ and Won Moon ${ }^{2}$ \\ ${ }^{1}$ Department of Internal Medicine, Jeju National University School of Medicine, Jeju, and ${ }^{2}$ Department of Internal Medicine, Kosin University \\ College of Medicine, Busan, Korea
}

New therapeutic strategies in inflammatory bowel disease (IBD) have shifted from symptom control towards treat-totarget algorithms in order to optimize treatment results. The treatment of IBD has evolved with the development of tumor necrosis factor- $\alpha$ inhibitors beyond the conventional therapies. In spite of their long-term effectiveness, many patients do not respond to or cannot sustain treatment with these drugs, which have various side effects. Therefore, the development of new drugs targeting specific pathways in the pathogenesis of IBD has become necessary. Some novel biologics and small molecule drugs have shown potential in IBD clinical trials, providing safe and effective results. In addition, clinicians are now trying to target the dysbiotic microbiome of patients with IBD using fecal microbiota transplantation. New tools such as stem cells have also been developed. The available therapeutic options for IBD are expanding rapidly. In the next few years, physicians will face an unprecedented number of options when choosing the best treatments for patients with IBD. This review provides an overview of recent advances in IBD treatment options. (Gut Liver 2019;13:604616)

Key Words: Inflammatory bowel diseases; Crohn disease; Colitis, ulcerative; Therapy

\section{INTRODUCTION}

Nonbiological therapies such as aminosalicylates, thiopurines, and steroids provide symptom improvement but do not change the overall disease course in inflammatory bowel diseases (IBDs) such as ulcerative colitis (UC) and Crohn's disease (CD). ${ }^{1}$ Biological therapies that use monoclonal antibody targeting of tumor necrosis factor- $\alpha$ (TNF- $\alpha$ ), such as infliximab, adalimumab, golimumab, and certolizumab pegol, were introduced in the late 1990s to induce and maintain remission. ${ }^{2-7}$ These biologics have led to the expectation that symptoms can be controlled and quality of life improved and even that the natural course of IBDs might eventually be changed. ${ }^{8-10}$ However, approximately one third of IBD patients are primary non-responders to TNF- $\alpha$ inhibitor induction therapy, ${ }^{6,711,12}$ and another one third become secondary non-responders during TNF- $\alpha$ inhibitor maintenance therapy. ${ }^{13-15}$ In addition, although the safety profile of TNF- $\alpha$ inhibitors is generally acceptable, these drugs do have adverse effects relating to infections and malignancies. ${ }^{16-18}$

As our understanding of the pathological mechanisms of IBDs has advanced, some novel drugs have shown potential in IBD clinical trials for providing safe and effective results. In addition, clinicians are now trying to target the dysbiotic microbiome of patients with IBD using fecal microbiota transplantation (FMT). New tools such as stem cells have also been developed, especially in the treatment of perianal CD. In the next few years, physicians will face an unprecedented number of options when choosing the best treatments for patients with IBD. This review provides an overview of recent advances in IBD treatment options.

\section{BIOLOGICS VERSUS SMALL MOLECULES}

Medications for IBD are classified into two categories, biologics and small molecule drugs. Biologics are monoclonal antibodies, large complex molecules that typically have a molecular weight of 150,000 Da, whereas small molecule drugs are less than $500 \mathrm{Da} .{ }^{19}$ Although biologics have a long half-life and high potency and selectivity, they are proteins that require a sterile living cell culture system and parenteral administration, and they have immunogenicity. ${ }^{19}$ Because patient immune systems

\footnotetext{
Correspondence to: Won Moon

Department of Internal Medicine, Kosin University College of Medicine, 262 Gamcheon-ro, Seo-gu, Busan 49267, Korea

Tel: +82-51-990-5207, Fax: +82-51-990-5055, E-mail: moonone70@hanmail.net

Received on January 14, 2019. Revised on February 22, 2019. Accepted on March 2, 2019. Published online June $17,2019$. pISSN 1976-2283 eISSN 2005-1212 https://doi.org/10.5009/gnl19019

(a) This is an Open Access article distributed under the terms of the Creative Commons Attribution Non-Commercial License (http://creativecommons.org/licenses/by-nc/4.0) which permits unrestricted non-commercial use, distribution, and reproduction in any medium, provided the original work is properly cited.
} 
recognize the proteins as foreign bodies, antibodies to biologics can block their efficacy over time, causing treatment failure. On the other hand, small molecules are simply well-defined chemical structures produced by chemical synthesis. Although they have a short half-life and less potency than biologics, their advantages include an oral route of administration, low cost, and non-immunogenicity. ${ }^{19}$

New biologics may offer opportunity for treatment with regard to the limitations of TNF- $\alpha$ inhibitors, even in patients who have previously failed with TNF- $\alpha$ inhibitors. Novel biologics include anti-integrins, anti-cytokines, and anti-mucosal vascular addressin cell adhesion molecule-1 (MAdCAM-1). Aminosalicylates, thiopurines, and steroids are small molecule drugs that have been used for a long time. Thiopurines showed poorly defined maintenance effects in many previous studies of UC and $\mathrm{CD} \cdot{ }^{20,21}$ Novel orally administered small molecules have the potential to replace preexisting small molecule drugs. However, the efficacy, long-term safety profile, and cost-effectiveness of the new drugs remain to be elucidated. Novel small molecules include Janus kinase (JAK) inhibitors, small mothers against decapentaplegic homolog (SMAD)7 antisense oligonucleotides, sphingosine-1-phosphate (S1P) receptor modulators, and phosphodiesterase (PDE) 4 inhibitors. The new biologics and small molecule drugs block immune cell communication or migration (Table 1, Fig. 1).

\section{RECENTLY APPROVED NOVEL DRUGS}

\section{Monoclonal antibodies}

\section{1) Anti-adhesion molecules}

IBDs are characterized by the persistent recruitment of large quantities of leukocytes from the blood to the gut mucosa. ${ }^{22}$ Interactions between several surface molecules on $\mathrm{T}$ cells called integrins ( $\alpha 4 \beta 7)$ and tissue-specific adhesion molecules called ligands (MAdCAM-1), which are primarily expressed in endothelial venules, are responsible for the lymphocyte recruitment into the intestine seen in chronic intestinal inflammation. ${ }^{23,24}$ Therefore, leukocyte traffic control, using specific integrin inhibitors to prevent gut-homing $\mathrm{T}$ cells from moving out of the blood vessels, has been developed as a novel treatment for IBD.

\section{Natalizumab (anti-integrin, $\alpha 4$ subunit)}

Natalizumab is a nonselective recombinant humanized monoclonal IgG4 antibody against the integrin subunit $\alpha 4$ that blocks both $\alpha 4 \beta 7$ and $\alpha 4 \beta 1 .^{23}$ The $\alpha 4 \beta 7 / M A d C A M-1$ interaction is gut specific. Phase 3 trials of natalizumab include ENACT-1, ENACT-2, and ENCORE. ENACT-1 was conducted to test the induction effect of natalizumab in 905 moderate to severe CD patients. ${ }^{25}$ At week 10, natalizumab showed favorable clinical response (56\% [408/724] vs 49\% [88/181], p=0.05) and similar remission (37\% [267/724] vs 30\% [55/181], p=0.12) compared with placebo. In the ENACT-2 comparing the maintenance effect at week 36, 339 patients who responded to natalizumab in ENACT-1 were divided into natalizumab and placebo groups; natalizumab demonstrated significantly higher clinical response (61\% [103/168] vs 28\% [48/170], p<0.001) and remission (44\% [57/130] vs $26 \%$ [31/120], $\mathrm{p}=0.03)$ than placebo. ${ }^{25}$ The ENCORE that investigated the induction effects of natalizumab. In 509 moderate to severe CD patients treated with natalizumab or placebo, natalizumab achieved superior clinical response (48\% [124/259] vs 32\% [81/250], $\mathrm{p}=0.002)$ and remission $(26 \%$ [68/259] vs $16 \%$ [40/250], $\mathrm{p}=0.002$ ) than placebo at week $12 .^{26}$

Natalizumab also inhibits the migration of T cell lymphocytes to the central nervous system by blocking the $\alpha 4 \beta 1 /$ vascular cell adhesion molecule (VCAM)-1 interaction. ${ }^{27}$ As a result, progressive multifocal leukoencephalopathy (PML) caused by John Cunningham (JC) virus reactivation has been reported as a fatal adverse event associated with natalizumab..$^{25,28,29}$ The estimated

Table 1. Classification of Novel Drugs According to Molecular Mass and Mechanism

\begin{tabular}{lcc}
\hline & \multicolumn{1}{c}{ Block immune cell migration } & Block immune cell communication \\
\hline Biologics & Anti-integrins: block receptors (integrins) on lymphocytes in & Anti-cytokines: block signals (cytokines) outside from \\
& recruiting from blood to tissue & interacting with receptors on lymphocytes surface \\
& Anti-MAdCAM-1: block ligands (MAdCAM-1) on vascular & \\
& endothelium in recruiting from blood to tissue & \\
Small molecule drugs & S1P receptor modulators: trap lymphocytes in lymph nodes & JAKs inhibitor: block cell surface receptor signals (JAKs) \\
& & inside lymphocytes \\
& & SMAD7 antisense oligonucleotide: block protein (SMAD7) \\
& from inhibit anti-inflammatory signaling inside \\
& lymphocytes \\
& PDE4 inhibitor: block enzyme (PDE4) from catalyze \\
& cAMP from inflammatory cascade inside lymphocytes
\end{tabular}

MAdCAM-1, mucosal vascular addressin cell adhesion molecule-1; S1P, sphingosine-1-phosphate; JAK, Janus kinase; SMAD, mothers against decapentaplegic homolog; PDE, phosphodiesterase; cAMP, cyclic adenosine monophosphate. 


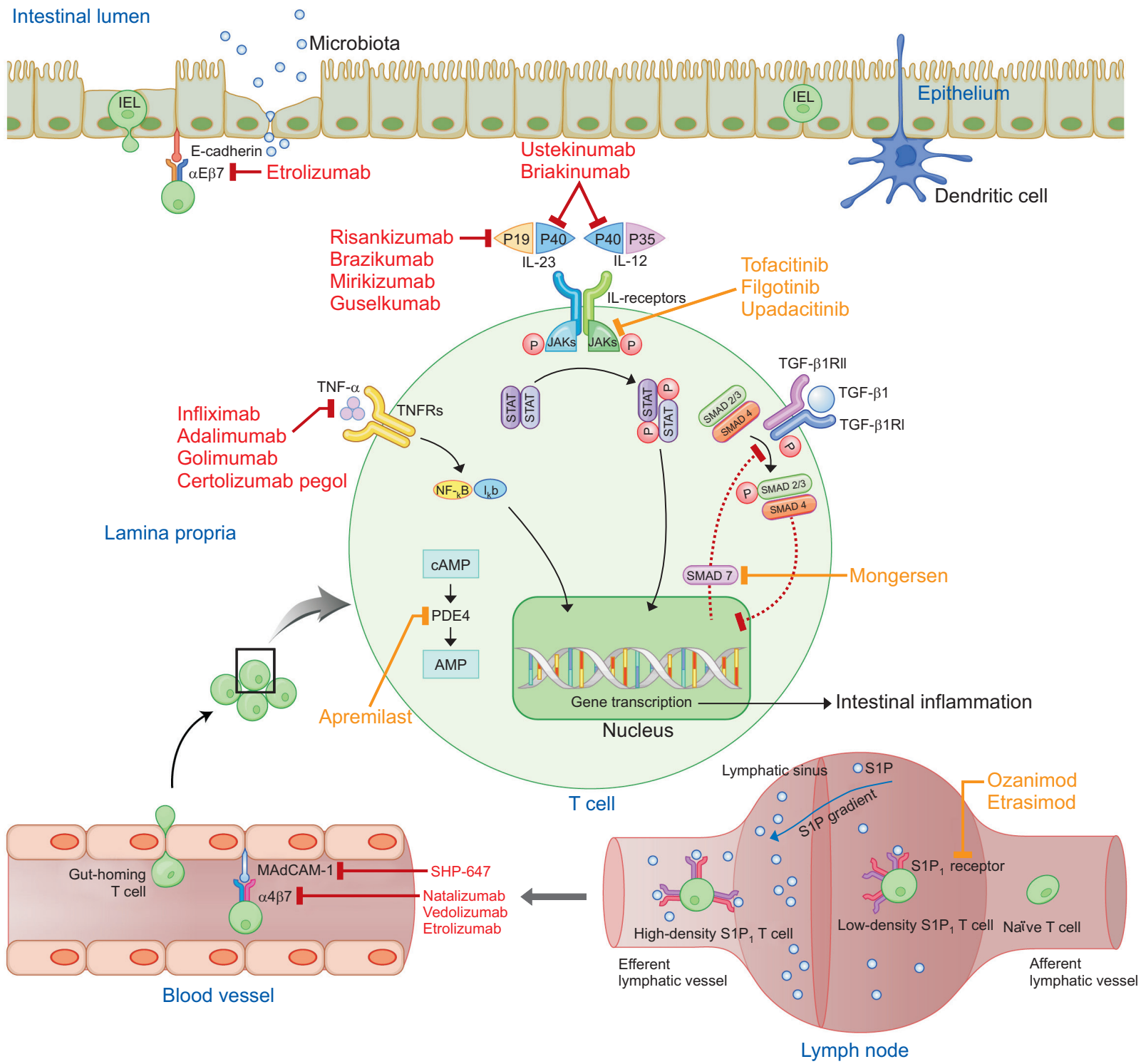

Fig. 1. Therapeutic targets of novel biologics and small molecules for the treatment of inflammatory bowel disease. Biologics and small molecules are indicated by red and orange colors, respectively.

AMP, adenosine monophosphate; cAMP, cyclic adenosine monophosphate; IEL, intraepithelial lymphocyte; Iкb, inhibitor of $\kappa \mathrm{B}$; IL, interleukin;

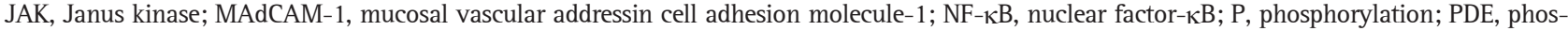
phodiesterase; S1P, sphingosine-1-phosphate; SMAD, mothers against decapentaplegic homolog; STAT, signal transducer and activator of transcription; TGF- $\beta$, transforming growth factor- $\beta$; TGF- $\beta$ R, TGF- $\beta$ receptor; TNF- $\alpha$, tumor necrosis factor- $\alpha$; TNFR, TNF receptor.

incidence of PML was 2 per 1,000 natalizumab-treated patients with multiple sclerosis, and having the JC virus antibody, prior use of immunosuppressants, and increased duration of natalizumab treatment were three major risk factors. ${ }^{30}$ Natalizumab was approved by U.S. Food and Drug Administration (FDA) in 2004 and temporarily withdrawn from the market in 2005 due to PML; it was reintroduced in 2006, but only in the United States. ${ }^{30}$ Natalizumab could be considered in patients who have had an inadequate response to or tolerability of conventional CD therapies and TNF- $\alpha$ inhibitors, but it should not be used in combination with immunosuppressants or TNF- $\alpha$ inhibitors. Only one open-label pilot study considered the effects of na- talizumab in UC patients. ${ }^{31}$ After a single infusion, natalizumab was well tolerated and showed weak but positive efficacy up to week 12; six patients achieved clinical response at week 4 , but only one of the 10 patients remained in remission at week 12 .

Vedolizumab (anti-integrin, $\alpha 4 \beta 7$ subunit)

Vedolizumab is a selective IgG1 monoclonal antibody against $\alpha 4 \beta 7$ integrin. ${ }^{22}$ Vedolizumab showed effective induction and maintenance of remission in phase 3 trials with both UC (GEMINI-1) and CD (GEMINI-2). In GEMINI-1, 374 moderate to severe UC patients were randomized, and 47.1\% (106/225) of patients who received vedolizumab induction therapy had a 
clinical response at week 6 compared with 25.5\% (38/149) of those in the placebo group $(\mathrm{p}<0.001){ }^{32}$ In maintenance therapy of 373 re-randomized induction responders, clinical remission was achieved at week 52 in 41.8\% (51/122) and 44.8\% (56/125) of patients who received vedolizumab every 8 and 4 weeks, respectively, and 15.9\% (20/126) of the patients receiving placebo $(\mathrm{p}<0.001) .^{32}$ In GEMINI-2, which had the same design as GEMINI-1, corresponding data were obtained in patients with moderate to severe CD; at week 6, 31.4\% (69/220) in the vedolizumab group had a clinical response (vs 25.7\% [38/148] in the placebo group, $p=0.23)$ and at week 52, 39.0\% (60/154) and 36.4\% (56/154) of patients who received vedolizumab every 8 and 4 weeks, respectively, were in clinical remission (vs $21.6 \%$ [33/153] in the placebo group, $\mathrm{p}<0.001$ and $\mathrm{p}=0.004$, respectively). ${ }^{33}$ A separate GEMINI-3 was conducted to evaluate the effects of vedolizumab induction in $315 \mathrm{CD}$ patients who failed on TNF- $\alpha$ inhibitors. ${ }^{34}$ Although the remission rates were not significant at week 6 (15.2\% [24/158] with vedolizumab vs $12.1 \%$ [19/157] with placebo, $p=0.433)$, therapeutic benefits of vedolizumab were detectable at week 10 (26.6\% [42/158] with vedolizumab vs $12.1 \%$ [19/157] with placebo, $\mathrm{p}=0.001$ ). In post-hoc analyses of data from GEMINI-1, vedolizumab demonstrated greater efficacy as an induction and maintenance therapy in UC patients naïve to TNF- $\alpha$ inhibitors than in those previously exposed to TNF- $\alpha$ inhibitors. ${ }^{35}$ The same trend of efficacy was demonstrated in CD in post-hoc analyses of data from GEMINI-2 and GEMINI-3. ${ }^{36}$ Notably, physicians should be aware of the potentially slow onset of action with vedolizumab, especially in $\mathrm{CD}$. This is a predictable result because vedolizum$\mathrm{ab}$ is an anti-adhesion molecule that blocks lymphocytes from moving blood to gut tissue. It takes time for preexisting immune cells in the inflamed tissue to disappear. Therefore, combined therapy with faster-acting induction agents such as steroids might be a good choice in hospitalized patients with a high inflammatory burden who need a rapid response. However, no randomized controlled trial has yet compared such a combination therapy with vedolizumab monotherapy. Another option in acute severe colitis might be TNF- $\alpha$ inhibitors. Although vedolizumab showed superior outcomes when given to patient naïve to TNF- $\alpha$ inhibitors, it is being positioned in some countries as a second-line biologic to follow TNF- $\alpha$ inhibitor therapy rather than as a first-line biological therapy. Excellent maintenance after successful induction with vedolizumab can be expected regardless of the type of IBD. Due to the gut-selective mechanism of vedolizumab, patients with extraintestinal manifestations might prefer other treatment options such as ustekinumab or a combination therapy with TNF- $\alpha$ inhibitors. The GEMINI longterm study is a continuing phase 3 trial, and two interim analyses were reported for the efficacy of vedolizumab in UC and CD. Among UC patients who responded to vedolizumab induction, 88\% (120/136) and 96\% (70/73) were in remission in weeks 104 and 152 after administration, respectively. ${ }^{37}$ Similarly, among
CD patients, 83\% (100/120) and 89\% (62/70) were in remission in weeks 104 and 152, respectively. ${ }^{38}$ The ongoing ENTERPRISE (evaluation of fistula at week 30 after vedolizumab administration up to week 22, NCT02630966) and EARNEST (evaluation of pouchitis at week 34 after vedolizumab administration up to week 30 along with ciprofloxacin up to week 4, NCT02790138) phase 4 trials will determine its effectiveness for the treatment of specific complications of $\mathrm{CD}$ and $\mathrm{UC}$, respectively.

The gut-selective action of vedolizumab has important clinical implications for its safety profile. ${ }^{39}$ In 5 years and more than 2,800 patients exposed to vedolizumab, no increased risk was found for any infection, including PML. ${ }^{40}$ Importantly, vedolizumab does not increase the risk of opportunistic infections, and the rate of malignancy is consistent with that naturally observed in patients with IBD..$^{40}$ For this reason, vedolizumab could be a good choice for IBD patients with contraindications to TNF- $\alpha$ inhibitors, such as a demyelinating disorder, congestive heart failure, lymphoma, and especially active or latent tuberculosis infections. On the other hand, one theoretical issue with the gut-specific mechanism of vedolizumab is the possibility of gastrointestinal infections and malignancies. However, in the published data, enteric infections were infrequent in vedolizumab-exposed patients, and the incidence of colorectal cancer was consistent with that generally seen in IBD patients. ${ }^{40}$ Recently, vedolizumab was approved by the U.S. FDA and the European Medicines Agency (EMA) for moderate to severe UC or CD patients who do not respond to conventional or TNF- $\alpha$ inhibitor therapy.

\section{2) Anti-cytokine molecules}

Interleukin (IL)-12 p35-p40 and IL-23 p19-p40 are proinflammatory heterodimeric cytokines that share a common $\mathrm{p} 40$ subunit and induce T helper cell (TH) 1 and TH17 differentiation, respectively, thereby leading to $\mathrm{T}$ cell immune responses. ${ }^{41}$ These cytokines are expressed by dendritic cells and macrophages. They are increased in the gut mucosa with inflammation of IBD patients. $^{42}$

\section{Ustekinumab (anti-IL-12/IL-23)}

Ustekinumab is a fully human IgG1k monoclonal antibody against the common p40 subunit of IL-12 and IL-23, and it reduces $\mathrm{T}$ cell activation. ${ }^{43}$ Ustekinumab demonstrated induction efficacy in both patients with TNF- $\alpha$ inhibitor failure (UNITI-1) and TNF- $\alpha$ inhibitor-naïve (UNITI-2) and maintenance efficacy (IM-UNITI) in a phase 3 trial of moderate to severe CD patients who experienced failure or unacceptable side effects with conventional therapies. ${ }^{44}$ The rates of response at week 6 among patients receiving ustekinumab at a dose of either 130 $\mathrm{mg}$ or $6 \mathrm{mg} / \mathrm{kg}$ were significantly higher than the rate among patients receiving placebo in the UNITI-1 (34.3\% [84/245], $33.7 \%$ [84/249], and 21.5\% [53/247], respectively, $\mathrm{p} \leq 0.003$ for both compared with placebo) and the UNITI-2 (51.7\% [108/209], 
55.5\% [116/209], and 28.7\% [45/209], respectively, $\mathrm{p}<0.001$ for both compared with placebo). In the IM-UNITI, maintenance groups received ustekinumab every 8 or 12 weeks; at week 44, $53.1 \%(68 / 128)$ and $48.8 \%(63 / 129)$, respectively, were in remission, compared with $35.9 \%$ (47/131) of those receiving placebo ( $p=0.005$ and $p=0.04$, respectively). Ustekinumab was an effective induction and maintenance therapy for moderate to severe CD patients who failed with TNF- $\alpha$ inhibitors or conventional treatments; however, the effect was better in TNF- $\alpha$ inhibitornaïve patients. ${ }^{44,45}$ Notably, as induction therapy, the efficacy of ustekinumab on symptoms appears to be similar to that of TNF- $\alpha$ inhibitors, and clinical benefit was observed as early as week 3. Thus, unlike vedolizumab, ustekinumab might be the preferred choice in severe $\mathrm{CD}$. In addition, because ustekinumab inhibits pro-inflammatory cytokines, it could be the best choice for patients with extraintestinal manifestations such as pyoderma, ankylosing spondylitis, or uveitis. Antidrug antibodies (ADAs) were present in only two patients who had received 130 $\mathrm{mg}$ of intravenous ustekinumab. At week 44, the incidence of ADAs remained low (2.3\% of 1,154 patients). Further studies are needed to determine its efficacy in mucosal healing, hospitalization, and surgery.

In the UNITI, adverse events and infections in the ustekinumab groups were similar to those in the placebo groups for up to 44 weeks. ${ }^{44}$ The IM-UNITI long-term extension data demonstrated that safety events were similar among all placebo and ustekinumab patients, including adverse events, serious adverse events, and serious infections from week 0 through week $96 .^{46}$ No serious opportunistic infection occurred except for one case of pulmonary tuberculosis in a region with endemic tuberculosis. Long-term clinical trials and registry data from the use of ustekinumab for psoriasis have confirmed that ustekinumab is generally well tolerated and that serious infections and malignancies are rare. ${ }^{47-49}$ Recently, ustekinumab was approved by the U.S. FDA and the EMA for the treatment of moderate to severe $\mathrm{CD}$. In moderate to severe UC, a phase 3 trial (UNIFI, NCT02407236) for efficacy and safety has just been completed, and the results have not yet been released.

\section{Small molecules}

\section{1) Blockage of downstream signaling}

The Janus kinases (JAK1, JAK2, JAK3, and TYK2) are intracellular signal mediators that interact with signal transducers and activators of transcription (STAT). ${ }^{50}$ The JAK-STAT signaling pathway, one of the best understood signaling transduction cascades, regulates the transcription of several genes. ${ }^{51}$ The JAK-STAT signaling pathway is critically important for immune cells and hematopoietic cells and is also involved in the growth, survival, development, and differentiation of a variety of cells. ${ }^{52}$ When JAK-STAT signal transduction is blocked, extracellular chemical signals are not transmitted to the intracellular nucleus, which reduces gut inflammation.

\section{Tofacitinib (JAK1/JAK3 inhibitor)}

Tofacitinib is an orally administered small molecule that mainly inhibits JAK1 and JAK 3 and blocks the downstream effects of a large subset of proinflammatory cytokines including IL-2, IL-3, IL-4, IL-5, IL-6, IL-12, IL-15, IL-21, and interferon- $\gamma$. $^{53}$ In a phase 3 trail, tofacitinib demonstrated efficacy in both inducing (OCTAVE-1 and OCTAVE-2) and maintaining (OCTAVE Sustain) remission in moderate to severe UC patients who had previously used conventional or TNF- $\alpha$ inhibitor therapies. ${ }^{54}$ In the OCTAVE-1 and OCTAVE-2 induction trials, 598 and 541 patients, respectively, were randomized. In OCTAVE-1, remission at week 8 occurred in 18.5\% (88/476) of the patients in the tofacitinib $10 \mathrm{mg}$ group versus $8.2 \%(10 / 122)$ in the placebo group ( $\mathrm{p}=0.007$ ); in OCTAVE-2, remission occurred in $16.6 \%$ $(71 / 429)$ versus $3.6 \%(4 / 112, \mathrm{p}<0.001)$, respectively. Notably, in both trials, the treatment effect was similar between those who had received previous TNF- $\alpha$ inhibitor therapy and those who had not. Further studies are needed to determine whether it is better to use tofacitinib before or after biologics. In addition, tofacitinib appeared to be a fast-acting induction agent, improving the partial Mayo Score after only 2 weeks of administration. Patients who completed the induction trials with a clinical response participated in OCTAVE Sustain. At week 52, clinical remission occurred in 34.3\% (68/198) of the patients in the $5 \mathrm{mg}$ tofacitinib group and $40.6 \%(80 / 197)$ of the patients in the $10 \mathrm{mg}$ tofacitinib group versus $11.1 \%(22 / 198)$ of the patients in the placebo group ( $\mathrm{p}<0.001$ for both compared with placebo). In addition, across all three OCTAVE trials, both $5 \mathrm{mg}$ and $10 \mathrm{mg}$ of tofacitinib were superior to placebo for the induction and maintenance of mucosal healing. Because tofacitinib is a small molecule, it is not limited by immunogenicity or loss of response. The measurement of drug concentration might not be meaningful because the average drug concentrations of small molecules were similar regardless of remission.

Tofacitinib targets multiple cytokine pathways, which might increase the risk of infection. In the OCTAVE, infections occurred at higher rates with tofacitinib than with placebo, including herpes zoster. ${ }^{54}$ The 4.4 years data from global clinical trials of tofacitinib indicates a safety profile similar to that observed in UC patients treated with biologic agents, except for the dosedependent higher incidence of herpes zoster infection (4.1; 95\% confidence interval [CI], 3.1 to 5.2). ${ }^{55}$ Therefore, combination therapy with other broad immunosuppressants might not be advisable. In addition, similar to findings from rheumatoid arthritis, lipid profiles and cardiovascular events increased in patients who received tofacitinib, though the clinical relevance of those changes is uncertain. ${ }^{54,56}$ Therefore, it is worth paying particular attention to patient selection when considering tofacitinib as a long-term maintenance therapy. The long-term safety and efficacy of tofacitinib is being evaluated in an ongoing, open-label, long-term extension study (OCTAVE Open, NCT01470612). Tofacitinib was approved for the treatment of moderate to se- 
vere UC patients by the U.S. FDA in June 2018. On the other hand, in a 4-week phase 2 trial $^{57}$ and phase $2 \mathrm{~b}$ induction and maintenance trial ${ }^{58}$ with $\mathrm{CD}$ patients, tofacitinib had no clinical efficacy in induction compared with placebo.

\section{NOVEL DRUGS CURRENTLY IN LATE-PHASE DEVELOP- MENT}

\section{Monoclonal antibodies}

\section{1) Anti-adhesion molecules}

Etrolizumab (anti-integrin, $\beta 7$ subunit)

Etrolizumab is a humanized IgG1 monoclonal antibody directed against the $\beta 7$ subunit of the $\alpha 4 \beta 7$ and $\alpha \mathrm{E} \beta 7$ integrins, which interact with MAdCAM-1 and E-cadherin, respectively. ${ }^{59}$ E-cadherin is expressed on the intestinal epithelium. It serves as a ligand in the homing behavior of gut intraepithelial lymphocytes. Binding to both $\alpha 4 \beta 7$ and $\alpha E \beta 7$ enables etrolizumab to block mucosal lymphocyte trafficking and intraepithelial leukocyte retention, respectively. ${ }^{60}$

Etrolizumab was evaluated in a phase 2 trial (EUCALYPTUS) of 124 moderate to severe UC patients who had not responded to conventional therapy, including two-thirds of TNF- $\alpha$ inhibitor non-responders. ${ }^{61}$ Patients were assigned to receive $100 \mathrm{mg}$ of etrolizumab at weeks 0,4 , and 8 or a $420 \mathrm{mg}$ loading dose followed by $300 \mathrm{mg}$ at weeks 2,4 , and 8 , or placebo. No patients $(0 / 41)$ in the placebo group had clinical remission at week 10 , compared with $21 \%$ of the patients $(8 / 39)$ in the etrolizumab $100 \mathrm{mg}$ group $(\mathrm{p}=0.004)$ and $10 \%(4 / 39)$ of the patients in the $300 \mathrm{mg}$ group $(\mathrm{p}=0.048)$. Adverse events occurred at a similar frequency in all three groups. The expression of E-cadherin in biopsy samples increased in patients in the etrolizumab groups who achieved clinical remission compared with those who did not $(\mathrm{p}=0.0022)$. Therefore, colonic biopsy could play a role as a predictive biomarker for better response to etrolizumab. Currently, several phase 3 trials for UC patients are being evaluated: a comparison of infliximab and etrolizumab (NCT02136069), a combination of etrolizumab and adalimumab (NCT02163759), the induction and maintenance of a clinical response in patients exposed to TNF- $\alpha$ inhibitors (HICKORY, NCT02100696), and response maintenance in patients naïve to TNF- $\alpha$ inhibitors (NCT02165215). Induction and maintenance (BERGAMOT, NCT02394028) and open-label extension (NCT02403323) trials are also under way for $\mathrm{CD}$ patients. Interim results from BERGAMOT cohort-1 showed tolerable safety and clinically meaningful endoscopic improvement up to week $14 .{ }^{62} \alpha \mathrm{E} \beta 7$ and $\alpha 4 \beta 7$ are differentially expressed in T lymphocyte effectors subsets in the peripheral blood and intestines, respectively, of IBD patients. Because etrolizumab has additional inhibitory effects on the $\alpha E \beta 7$-mediated retention of lymphocytes in the gut epithelium compared with vedolizumab, it could inhibit inflammation in the intestine more strongly than vedolizumab. However, if $\beta 7$ integrin is blocked, it could reduce gut specificity because $\alpha E \beta 7$ is expressed by $\mathrm{T}$ cells in other tissues as well as in the intestines. Subsequent local infections outside the intestine can be a problem. Ongoing phase 3 trials (HICKORY, BERGAMOT) could determine whether latent infection is a significant adverse effect of etrolizumab.

\section{SHP-647 (PF-00547659, anti-MAdCAM-1)}

SHP-647 is a fully humanized monoclonal anti-MAdCAM IgG2 antibody directed against the gut-specific endothelial adhesion molecule MAdCAM- $1 .^{63}$ Phase 2 trials were conducted separately in UC and CD patients. In the TURANDOT, 357 moderate to severe UC patients were randomized to receive 7.5, 22.5, 75, or $225 \mathrm{mg}$ of SHP-647 or placebo. At week 12, clinical remission rates were 11.3\% (8/71), 16.7\% (12/72), and 15.5\% (11/71), and 5.7\% (4/70) for 7.5, 22.5, 75, and $225 \mathrm{mg}$, respectively, versus $2.7 \%(2 / 73)$ in the placebo group $(\mathrm{p}=0.0425$, $\mathrm{p}=0.0099, \mathrm{p}=0.0119, \mathrm{p}=0.1803$, respectively, against placebo). ${ }^{64}$ However, in contrast, the OPERA study in 265 moderate to severe $\mathrm{CD}$ patients did not demonstrate any therapeutic benefits compared with placebo response. ${ }^{65}$ SHP-647 was well tolerated in long-term phase 2 trials in UC patients up to week 144 (TURANDOT-2, NCT01771809) and in CD patients up to week 72 (OPERA-2, NCT01298492). Phase 3 trials for CD induction therapy (CARMEN CD 305, NCT03559517 and CARMEN CD 306, NCT03566823) and UC induction (FIGARO UC 301, NCT03259334 and FIGARO UC 302, NCT03259308) and maintenance (FIGARO UC 303, NCT03290781) therapy are currently in the recruitment phase.

\section{2) Anti-cytokine molecules}

Risankizumab, brazikumab, mirikizumab, and guselkumab (anti-IL-23)

Risankizumab is a fully humanized IgG1 monoclonal antibody directed against the p19 subunit of IL-23, similar to ustekinumab. Risankizumab was tested as an induction therapy for $\mathrm{CD}$ in a phase 2 trial of 121 moderate to severe $\mathrm{CD}$ patients who were randomized to receive $200 \mathrm{mg}$ or $600 \mathrm{mg}$ of risankizumab or placebo at weeks 0,4 , and $8 .^{66}$ At week $12,24 \%$ of the patients (10/41) who received $200 \mathrm{mg}$ of risankizumab $(\mathrm{p}=0.31)$ and 37\% (15/41) who received the $600 \mathrm{mg}$ dose had clinical remission versus $15 \%(6 / 39)$ of the placebo group ( $p=0.0252$ ). Notably, these results were obtained in a patient population in which $93 \%$ of patients had been previously treated with TNF- $\alpha$ inhibitors. Adverse effects of the risankizumab were similar to that of the placebo. A long-term extension trial showed clinical remission in $71 \%(44 / 62)$, clinical response in $81 \%$ (50/62), endoscopic remission in 35\% (22/62), and endoscopic response in 55\% (34/62) of patients. ${ }^{67}$ Phase 3 trials for induction and maintenance therapy in moderate to severe $\mathrm{CD}$ patients (NCT03105128, NCT03104413) and a phase 2 trial for moderate to severe UC patients (NCT03398148) are currently active and in recruiting. 
A phase 2a trial evaluated brazikumab in 119 moderate to severe CD patients who had failed with TNF- $\alpha$ inhibitors. ${ }^{68} \mathrm{~Pa}-$ tients were assigned to receive either $700 \mathrm{mg}$ of brazikumab or placebo at weeks 0 and 4. At week 8 , clinical response had been achieved in 49.2\% (29/59) of patients receiving brazikumab compared with $26.7 \%(16 / 60)$ receiving placebo $(p=0.01)$. The most common adverse events were headache and nasopharyngitis. High level of serum IL-22, a cytokine whose expression is induced by IL-23, was a predictive biomarker for a better response to brazikumab. However, another phase $2 \mathrm{~b}$ study with different doses and regimens was terminated (NCT02574637). A new phase 2 trial (EXPEDITION, NCT03616821) for moderate to severe UC patients is currently in recruiting.

Mirikizumab is currently being studied in a phase 2 trial of CD patients (SERENITY, NCT02891226). In UC, a phase 2 trial (NCT02589665) has been completed, but the results have not yet been released. Three phase 3 trials for induction (LUCENT-1, NCT03518086), maintenance (LUCENT-2, NCT03524092), and long-term extension (LUCENT-3, NCT03519945) in moderate to severe UC patients recently started recruiting. Clinical trials of other IL-23p19 antibodies, guselkumab for CD (phase 2, GALAXI-1, NCT03466411) and UC (phase 2, VEGA, NCT03662542) are currently in recruiting.

\section{Briakinumab (anti-IL-12/IL-23)}

Like ustekinumab, briakinumab is a human monoclonal antibody against the common p40 subunit of IL-12 and IL-23. In a preliminary phase $2 \mathrm{a}$ trial, briakinumab showed no significant difference for induction of remission in moderate to severe $\mathrm{CD}{ }^{69}$ Another phase $2 \mathrm{~b}$ trial also failed to show significant difference in remission rate at induction phase in 246 moderate to severe CD patients. $^{70}$ At week 6, $400 \mathrm{mg}$ and $700 \mathrm{mg}$ of briakinumab enter clinical remission in 13.3\% (6/45) and 17.3\% (24/139), respectively, compared with placebo 8.7\% (4/46) ( $\mathrm{p}=0.455$ and $\mathrm{p}=0.157$, respectively, compared with placebo). However, at week 12 , a significantly greater proportion of patients in the briakinumab $400 \mathrm{mg}(28.9 \%, \mathrm{p}=0.030)$ but not the $700 \mathrm{mg}$ group $(22.3 \%, p=0.087)$ were in remission compared with patients in the placebo group (10.9\%). In both trials, briakinumab appear to be safe. In UC, no clinical trial has yet been reported.

\section{Small molecules}

\section{1) Blockage of downstream signaling}

Filgotinib, upadacitinib (JAK1 inhibitor)

Filgotinib, a selective JAK1 inhibitor, demonstrated efficacy in 174 moderate to severe CD patients in a phase 2 trial (FITZROY). ${ }^{71}$ Clinical remission at week 10 was achieved in $47 \%$ (60/128) of patients treated with $200 \mathrm{mg}$ of filgotinib versus $23 \%(10 / 44)$ of patients treated with placebo $(p=0.0077)$. Up to week 20, filgotinib showed an acceptable safety profile. The effect was much less impressive among patients with previous exposure to TNF- $\alpha$ inhibitors (37\% vs $29 \%$ for filgotinib and placebo, respectively). Further phase 2 trials in fistulizing CD (NCT03077412) and small bowel disease CD (NCT03046056), as well as several phase 3 trials in UC (SELECTION-1, NCT02914522 and SELECTIONLTE, NCTO2914535) and CD (DIVERSITY-1, NCT02914561 and DIVERSITYLTE, NCT02914600) are ongoing.

Upadacitinib showed efficacy as an induction therapy in 180 moderate to severe $\mathrm{CD}$ patients in a phase 2 trial (CELEST, NCT02365649). ${ }^{72}$ At week 16 of induction, numerically more patients on $6 \mathrm{mg}$ of upadacitinib twice a day achieved clinical remission compared with placebo (27\% [10/37] vs $11 \%$ [4/37], $\mathrm{p}=0.1$ ). However, significantly more patients achieved endoscopic remission with $24 \mathrm{mg}$ of upadacitinib twice a day compared with placebo $(22 \%$ [8/36] vs $0 \%$ [0/37], $\mathrm{p}=0.01)$. The safety profile was as expected with a JAK inhibitor in this population. Currently, several phase 3 trials for induction are ongoing in $\mathrm{CD}$ patients both with (NCT03345836) and without (NCT03345849) TNF- $\alpha$ inhibitors experience, and maintenance (NCT02782663) and long-term extension (NCT03345823) therapy trials are also ongoing. In addition, phase 3 trials for UC (NCT02819635, NCT03653026, and NCT03006068) are also being evaluated.

\section{Mongersen (SMAD7 antisense oligonucleotide)}

Transforming growth factor $\beta 1$ (TGF- $\beta 1$ ) is a pleiotropic cytokine that has anti-inflammatory properties and plays an important role in cell homeostasis. In IBD, TGF- $\beta 1$ is highly produced but unable to signal through the TGF- $\beta$ receptor-associated SMAD pathway to suppress the production of inflammatory molecules. ${ }^{73}$ Abnormally decreased activity of TGF- $\beta 1$ in IBD is related to increased levels of SMAD7, an intracellular protein that binds to TGF- $\beta$ receptors and inhibits TGF- $\beta 1$-assocated and SMAD-associated signaling. ${ }^{74}$ Therefore, SMD7 is a potential target for the suppression of IBD-associated inflammation. ${ }^{73}$

Mongersen is a novel oral drug containing the specific SMAD7 antisense oligonucleotide. ${ }^{75}$ A phase 2 trial was conducted among 166 moderate to severe $\mathrm{CD}$ patients who were assigned to one of three doses of mongersen $(10,40$, or $160 \mathrm{mg} /$ day $)$ or placebo for 2 weeks. $^{76}$ Clinical remission rates at day 15 were 55\% (22/40) and 65\% (28/43) for the 40 and $160 \mathrm{mg} /$ day groups, respectively, versus $10 \%(4 / 42)$ in the placebo group ( $p<0.001$ for both comparisons with placebo), but the $10 \mathrm{mg}$ dose of mongersen $(12 \%, 5 / 41)$ failed to show significant efficacy. Most adverse effects were related to either symptoms or complications of $\mathrm{CD}$. However, a phase 3 clinical trial evaluating the efficacy and safety of mongersen in CD patients was recently terminated and withdrawn because it failed to show anything like the phase 2 successes (NCT02596893, NCT02974322, and NCT02641392). A small phase 2 open label trial for UC has been completed (NCT02601300), and the results have not yet been released. 
Apremilast (PDE4 inhibitor)

PDE4 is one of the enzymes that catalyze the breakdown of cyclic adenosine monophosphate (cAMP) to AMP in several types of cells, including inflammatory cells, and is considered to be an important player in the intracellular inflammatory cascade. ${ }^{77}$ PDE4 inhibitors increase intracellular levels of cAMP, which consequently downregulates the release of pro-inflammatory cytokines in the mucosa of IBD patients. ${ }^{77}$

Apremilast specifically targets PDE4 and could show efficacy in IBD treatment. Interim results of a phase 2 study (NCT02289417) were recently presented and demonstrated its effectiveness in 170 moderate to severe UC patients. ${ }^{78}$ At week 12, total Mayo Score remission was achieved in 31.6\% (18/57) of the group receiving $30 \mathrm{mg}$ of apremilast twice a day compared with $13.8 \%(8 / 58)$ of the placebo group $(p<0.05)$. However, the group receiving $40 \mathrm{mg}$ of apremilast twice a day (21.8\% of 55 patients) did not show significant difference. There were no new safety reports. In $\mathrm{CD}$, no clinical trial has yet been reported.

\section{2) Anti-trafficking molecules}

$\mathrm{S} 1 \mathrm{P}$ is a bioactive sphingolipid that mediates cellular responses in different cell types via extracellular activation of S1P receptor $1\left(\mathrm{~S}_{1} \mathrm{P}_{1}\right)$ to $\mathrm{S}_{1} \mathrm{P}_{5}{ }^{79} \mathrm{~S}_{1} \mathrm{P}_{1}, \mathrm{~S}_{1} \mathrm{P}_{4}$ and $\mathrm{S}_{1} \mathrm{P}_{5}$ are involved in regulating the immune system and expressed on lymphocytes and endothelial cells in lymph nodes, whereas $\mathrm{S}_{1} \mathrm{P}_{2}$ and $\mathrm{S} 1 \mathrm{P}_{3}$ could be associated with cardiovascular, pulmonary, and cancer-related risks. ${ }^{80}$ Lymphocytes migrate from regional lymph nodes into the blood vessels according to the S1P concentration gradient. ${ }^{81}$ Stimulation of $\mathrm{S} \mathrm{P}_{1}$ on lymphocytes results in the internalization and degradation of the target receptor. ${ }^{82}$ Consequently, lymphocytes could not follow the S1P gradient on the lymphatic endothelium, which induces peripheral lymphocyte sequestration and decreases the number of activated lymphocytes recruiting to the intestine. ${ }^{79}$

Ozanimod, etrasimod (S1P receptor modulator)

Ozanimod is a novel, oral, small-molecule $\mathrm{S}_{1} \mathrm{P}_{1}$ and $\mathrm{S}_{1} \mathrm{P}_{5}$ agonist, mainly $\mathrm{S}_{1} \mathrm{P}_{1} \cdot{ }^{83}$ A phase 2 trial (TOUCHSTONE) evaluated the induction and maintenance treatment of ozanimod in 197 moderate to severe UC patients. ${ }^{84}$ The patients were randomized to placebo, 0.5 , or $1 \mathrm{mg}$ of ozanimod daily. At week 8 , clinical remission was achieved in $16 \%(11 / 67)$ of the patients who received $1 \mathrm{mg}$ of ozanimod and 14\% (9/65) of those who received $0.5 \mathrm{mg}$ of ozanimod, as compared with 6\% (4/65) of those who received placebo $(\mathrm{p}=0.048$ and $\mathrm{p}=0.14$, respectively, compared with placebo). At week 32, clinical remission was $21 \%$ in the group $(14 / 67)$ that received $1 \mathrm{mg}$ of ozanimod, $26 \%(17 / 65)$ in the group that received $0.5 \mathrm{mg}$ of ozanimod, and $6 \%(4 / 65)$ in the group that received placebo $(p=0.01$ and $p=0.002$, respectively, compared with placebo). Ozanimod was well tolerated, and the most common adverse events were ane- mia and headache. Interim results from a phase 3 long-term open-label trial (TOUCHSTONE, NCT02531126) indicated that $1 \mathrm{mg}$ ozanimod appears to be well tolerated, with evidence of rapid onset and durable efficacy up to week 104 with no rectal bleeding in $88.2 \%$ patients. ${ }^{85}$ A phase 3 trial of ozanimod as an induction and maintenance therapy for UC is currently ongoing (NCT02435992). Initial results from a phase 2 trial (STEPSTONE, NCT02531113) of 69 patients treated with ozanimod for moderate to severe $\mathrm{CD}$ demonstrated meaningful clinical and endoscopic improvements at week 12 in both biologic-naïve and biologic-experienced patients. ${ }^{85}$ Currently, phase 3 trials of ozanimod in moderate to severe CD patients are ongoing for induction and maintenance, along with an open-label longterm efficacy and safety trial (NCT03440372, NCT03440385, NCT03464097, and NCT03467958).

Etrasimod is a compound similar to ozanimod that selectively targets $\mathrm{S}_{1} \mathrm{P}_{1}, \mathrm{~S}_{1} \mathrm{P}_{4}$ and $\mathrm{S}_{1} \mathrm{P}_{5}$ in in vitro assays. ${ }^{80}$ Initial results from a phase 2 trial (OASIS, NCT201447302) in 156 moderate to severe UC patients treated with etrasimod showed that it was effective in achieving dose-dependent improvements in endoscopic appearance (22.5\% (12/52), 41.8\% (21/50), and 17.8\% (10/54) for etrasimod $1 \mathrm{mg}, 2 \mathrm{mg}$, and placebo, respectively, $\mathrm{p}=0.306, \mathrm{p}=0.03$ compared with placebo). ${ }^{86}$ Etrasimod was safe and well tolerated in this short-term study. Etrasimod is currently being tested in a parallel extension phase 2 trial for moderate to severe UC (NCT02536404). In CD, no clinical trials have yet been reported.

\section{OTHERS}

\section{Novel combinations}

Drug combinations, such as those commonly used in the treatment of diabetes or hypertension, could be a way to take advantage of the strengths and make up for the weaknesses of both biologics and small molecules. The SONIC and SUCCESS trials combining infliximab and azathioprine showed the potential of combination therapy. ${ }^{87,88}$ On the other hand, the DIAMOND trial, which combined adalimumab with azathioprine, failed to show clinical improvement in the remission rate compared with adalimumab monotherapy in CD patients, though mucosal healing was significantly higher in the combination group. ${ }^{89}$ Similarly, GEMINI-1 and 2 showed that concomitant immunosuppressive therapy with vedolizumab was associated with decreased immunogenicity. ${ }^{32}$ The co-administration of immunosuppressive drugs at baseline decreased the ADA positivity rate by $1 \%$, from $4 \%$ to $3 \%$. Further studies are needed to determine whether combination therapy with immunosuppressive drugs offers the same clinical advantages for vedolizumab as seen with infliximab/azathioprine combination therapy. Ustekinumab appears to be less immunogenic than the TNF- $\alpha$ inhibitors. In the IM-UNITI, the incidence of ADAs to ustekinumab at week 44 was low, only $2.3 \%$ of patients 
$(27 / 1,154) .^{44}$ Although combination therapy with immunosuppressives might reduce ADAs compared with ustekinumab monotherapy, the clinical benefit remains unknown.

The availability of several biologics for the treatment of IBDs offers the possibility of combining them to simultaneously antagonize different pathways, which could produce additive or synergistic effects for the refractory disease. In 2007, Sands et $a l^{90}$ conducted a randomized trial of the efficacy and safety of concurrent natalizumab in $79 \mathrm{CD}$ patients not in remission while receiving infliximab. That study showed that symptoms tended to improve in the natalizumab/infliximab arm (52 patients) compared with the placebo/infliximab arm (27 patients) (CDAI score reduction, -37.7 vs +3.5 , $\mathrm{p}=0.084$ ), with comparable adverse effects. Since then, several anecdotal case reports of combinations such as infliximab plus vedolizumab, etanercept plus vedolizumab, and ustekinumab plus infliximab or adalimumab have been reported. ${ }^{91}$ Recently, an open label phase 4 trial evaluating the triple combination therapy of vedolizumab, adalimumab, and methotrexate (EXPLORER, NCT02764762) has started enrolling 60 patients with high risk CD. However, that combination therapy faces some potential issues, such as blocking opposing pathways and subsequent increased side effects, in addition to increased costs.

\section{Fecal material transplantation}

FMT is currently suggested in the guideline as a treatment option in refractory Clostridium difficile-associated colitis. ${ }^{92,93}$ Although FMT was also proposed as a treatment method for IBD about 30 years ago, ${ }^{94}$ interest and investigation of it as a potential treatment for IBD has grown only in the past few years. A meta-analysis of 53 studies, 41 in UC, 11 in CD, and 4 in pouchitis, comprising 661 IBD patients showed that 36\% of UC patients (201/555), 50.5\% of CD patients (42/83), and 21.5\% (5/23) of pouchitis patients undergoing FMT achieved clinical remission. ${ }^{95}$ In a sub-analysis of 24 studies, microbiota analyses showed increased diversity and a shift in the recipient microbiota profile toward the donor. In another meta-analysis of four randomized controlled trials for UC, FMT was associated with higher clinical remission (risk ratio, 0.76; 95\% CI, 0.62 to 0.93) and endoscopic remission (risk ratio, 0.85; 95\% CI, 0.69 to 1.05) compared with placebo. ${ }^{96}$ No significant increase in serious adverse events was observed. FMT has showed promise as a treatment for IBD, especially UC, in many studies. FMT as a treatment for UC appears very promising, especially with multiple infusions administered via the lower gastrointestinal tract. The role of FMT in CD remains unclear yet. Most patients in the studies done so far had mild to moderate UC, and it is unclear whether the efficacy will be similar, better, or worse in patients with severe disease. Some unanswered questions require fur-

Table 2. Pipeline of Novel Pharmacologic Treatment Agents for Inflammatory Bowel Disease

\begin{tabular}{|c|c|c|c|c|c|c|}
\hline \multirow{2}{*}{ Mechanism } & \multirow{2}{*}{ Drug } & \multirow{2}{*}{ Type } & \multirow{2}{*}{ Target } & \multirow{2}{*}{ Route } & \multicolumn{2}{|c|}{ Current status in IBD } \\
\hline & & & & & UC & $\mathrm{CD}$ \\
\hline \multirow{4}{*}{$\begin{array}{l}\text { Anti-adhesion } \\
\text { molecules }\end{array}$} & Natalizumab & Chimeric mAb & Anti-integrin ( $\alpha 4$ subunit) & IV & Phase 2a & Approved \\
\hline & Vedolizumab & Chimeric mAb & Anti-integrin ( $\alpha 4 \beta 7$ subunit) & IV & Approved & Approved \\
\hline & Etrolizumab & Chimeric mAb & Anti-integrin ( $\beta 7$ subunit) & IV/SC & Phase 3 & Phase 3 \\
\hline & SHP-647 & Fully human mAb & Anti-MAdCAM-1 & SC & Phase 3 & Phase 3 \\
\hline \multirow{6}{*}{$\begin{array}{l}\text { Anti-cytokine } \\
\text { molecules }\end{array}$} & Ustekinumab & Fully human mAb & Anti-IL-12/IL-23 (p40) & IV/SC & Phase 3 & Approved \\
\hline & Risankizumab & Fully human mAb & Anti-IL-23 (p19) & IV/SC & Phase 2 & Phase 3 \\
\hline & Brazikumab & Fully human mAb & Anti-IL-23 (p19) & IV/SC & Phase 2 & Phase 2 \\
\hline & Mirikizumab & Chimeric mAb & Anti-IL-23 (p19) & IV/SC & Phase 3 & Phase 2 \\
\hline & Guselkumab & Fully human mAb & Anti-IL-23 (p19) & IV/SC & Phase 2 & Phase 2 \\
\hline & Briakinumab & Fully human mAb & Anti-IL-12/IL-23 (p40) & IV/SC & - & Phase $2 b$ \\
\hline \multirow{5}{*}{$\begin{array}{l}\text { Blockage of } \\
\text { downstream } \\
\text { signaling }\end{array}$} & Tofacitinib & Small molecule & JAK1/JAK3 inhibitor & Oral & Approved & Phase 2 \\
\hline & Filgotinib & Small molecule & JAK1 inhibitor & Oral & Phase 3 & Phase 3 \\
\hline & Upadacitinib & Small molecule & JAK1 inhibitor & Oral & Phase 3 & Phase 3 \\
\hline & Mongersen & Small molecule & SMAD7 antisense oligonucleotide & Oral & Phase 2 & Withdrawn \\
\hline & Apremilast & Small molecule & PDE4 inhibitor & Oral & Phase 2 & - \\
\hline \multirow{2}{*}{$\begin{array}{l}\text { Anti-trafficking } \\
\text { molecules }\end{array}$} & Ozanimod & Small molecule & $\mathrm{S} 1 \mathrm{P}$ receptor modulator & Oral & Phase 3 & Phase 3 \\
\hline & Etrasimod & Small molecule & S1P receptor modulator & Oral & Phase 2 & - \\
\hline
\end{tabular}

IBD, inflammatory bowel disease; UC, ulcerative colitis; CD, Crohn's disease; mAb, monoclonal antibody; IV, intravenous; SC, subcutaneous; MAdCAM-1, mucosal vascular addressin cell adhesion molecule-1; IL, interleukin; JAK, Janus kinase; SMAD, mothers against decapentaplegic homolog; PDE, phosphodiesterase; S1P, sphingosine-1-phosphate. 
ther research before FMT can be considered for use in clinical practice. For example, it is unclear whether pooled or single donor is better. To date, no trials have attempted a microbiome analysis-informed strategy for donor selection. In addition, if repeated FMT is needed because IBD is a chronic disease, how many and how frequently will they be required, and what is the most effective infusion method, duodenal infusion, colonoscopic infusion, or enemas? Do encapsulated stool pills work as an endoscopic FMT? Above all, long-term durability and safety remain unclear. Therefore, additional well-designed controlled trials of FMT in IBD are needed and many new trials are already in progress.

\section{Stem cell transplantation}

Recently, mucosal healing has become a required part of clinical response and a treatment goal based on treat-to-target therapeutic strategies in IBD. ${ }^{97}$ In line with these tactics, new stem cell therapy that can promote mucosal tissue regeneration has been highlighted in IBD. ${ }^{98}$ Stem cell biology can be applied using two different methods. First, hematopoietic stem cell transplantation (HSCT) has been considered for the treatment of refractory CD. Myeloablation of the subject patient, followed by HSCT could set the patient's immunological condition back to before the disease developed. A phase 3 trial (ASTIC) in 45 patients with refractory $\mathrm{CD}$ was terminated because no significant improvement was found in sustained disease remission at 1 year compared with conventional therapy (8.7\% of 23 patients vs $4.5 \%$ of 22 patients, $\mathrm{p}=0.60$ ), with increased toxicity including one fetal mortality. ${ }^{99}$ A phase 2 trial (MASCT-CD, NCT03219359) combining HSCT with vedolizumab to improve the chances of achieving and maintaining the remission has begun and is in recruitment. Second, mesenchymal stem cell transplantation (MSCT) is in clinical trials to treat UC and luminal CD (intravenous administration, allogenic) or fistulizing CD (intralesional injection, autologous). MSCT can exhibit both immunoregulatory functions and tissue regenerative functions upon transplantation and can be widely used for allogenic transplantation because of its low immunogenicity. A phase 3 trial of $212 \mathrm{CD}$ patients demonstrated that intralesional injectable autologous MSCT is an effective and safe treatment compared with placebo for complex perianal fistulas in patients who did not respond to conventional or biological treatments. ${ }^{100}$ At week 24, remission with closure of all treated external openings was achieved in 50\% (53/107) and 34\% (36/105) $(\mathrm{p}=0.024)$ of the MSCT and placebo groups, respectively. A phase 3 trial (NCT00482092) of 330 moderate to severe CD patients used an intravenous infusion of allogenic MSCT delivered through a vein in the arm of healthy adult donors and is expected to report favorable data in the near future. Currently, intralesional autologous MSCT has been commercialized for perianal fistulizing $\mathrm{CD}$ and many stem cell-related trials are underway.

\section{CONCLUSION}

The newly approved and potentially novel drugs for the treatment of IBD described above are summarized in Table 2. New therapeutic strategies are evolving including early diagnosis, early intervention, tight control of biomarkers, and treat-totarget algorithms in order to optimize treatment results, and available therapeutic options for IBD are expanding rapidly. It might soon be possible to achieve those new therapeutic strategies and goals with the support of novel drugs, microbiome manipulations, and stem cells targeting specific pathways in IBD pathogenesis. A new, challenging era is coming for clinicians who must choose the best therapy for their IBD patients. Physicians involved in the management of IBD should have expertise to understand and properly apply the various treatment options in the near future.

\section{CONFLICTS OF INTEREST}

No potential conflict of interest relevant to this article was reported.

\section{ORCID}

Won Moon https://orcid.org/0000-0002-3963-8680

\section{REFERENCES}

1. Burger D, Travis S. Conventional medical management of inflammatory bowel disease. Gastroenterology 2011;140:1827-1837.

2. Rutgeerts P, Sandborn WJ, Feagan BG, et al. Infliximab for induction and maintenance therapy for ulcerative colitis. N Engl J Med 2005;353:2462-2476.

3. Reinisch W, Sandborn WJ, Hommes DW, et al. Adalimumab for induction of clinical remission in moderately to severely active ulcerative colitis: results of a randomised controlled trial. Gut 2011;60:780-787.

4. Sandborn WJ, van Assche G, Reinisch W, et al. Adalimumab induces and maintains clinical remission in patients with moderateto-severe ulcerative colitis. Gastroenterology 2012;142:257-265.

5. Targan SR, Hanauer SB, van Deventer SJ, et al. A short-term study of chimeric monoclonal antibody cA2 to tumor necrosis factor alpha for Crohn's disease. Crohn's Disease cA2 Study Group. N Engl J Med 1997;337:1029-1035.

6. Hanauer SB, Sandborn WJ, Rutgeerts P, et al. Human anti-tumor necrosis factor monoclonal antibody (adalimumab) in Crohn's disease: the CLASSIC-I trial. Gastroenterology 2006;130:323-333.

7. Schreiber S, Khaliq-Kareemi M, Lawrance IC, et al. Maintenance therapy with certolizumab pegol for Crohn's disease. N Engl J Med 2007;357:239-250.

8. Sokol H, Seksik P, Cosnes J. Complications and surgery in the inflammatory bowel diseases biological era. Curr Opin Gastroen- 
terol 2014:30:378-384.

9. Yarur AJ, Kanagala V, Stein DJ, et al. Higher infliximab trough levels are associated with perianal fistula healing in patients with Crohn's disease. Aliment Pharmacol Ther 2017;45:933-940.

10. Amiot A, Setakhr V, Seksik P, et al. Long-term outcome of enterocutaneous fistula in patients with Crohn's disease treated with anti-TNF therapy: a cohort study from the GETAID. Am J Gastroenterol 2014;109:1443-1449.

11. Sandborn WJ, Hanauer SB, Rutgeerts $P$, et al. Adalimumab for maintenance treatment of Crohn's disease: results of the CLASSIC II trial. Gut 2007;56:1232-1239.

12. Hanauer SB, Feagan BG, Lichtenstein GR, et al. Maintenance infliximab for Crohn's disease: the ACCENT I randomised trial. Lancet 2002;359:1541-1549.

13. Allez M, Karmiris K, Louis E, et al. Report of the ECCO pathogenesis workshop on anti-TNF therapy failures in inflammatory bowel diseases: definitions, frequency and pharmacological aspects. J Crohns Colitis 2010;4:355-366.

14. D'Haens GR, Panaccione R, Higgins PD, et al. The London Position Statement of the World Congress of Gastroenterology on Biological Therapy for IBD with the European Crohn's and Colitis Organization: when to start, when to stop, which drug to choose, and how to predict response? Am J Gastroenterol 2011;106:199212.

15. Ben-Horin S, Chowers Y. Review article: loss of response to antiTNF treatments in Crohn's disease. Aliment Pharmacol Ther 2011;33:987-995.

16. Toruner M, Loftus EV Jr, Harmsen WS, et al. Risk factors for opportunistic infections in patients with inflammatory bowel disease. Gastroenterology 2008;134:929-936.

17. Andersen NN, Jess T. Risk of infections associated with biological treatment in inflammatory bowel disease. World J Gastroenterol 2014;20:16014-16019.

18. Siegel CA, Marden SM, Persing SM, Larson RJ, Sands BE. Risk of lymphoma associated with combination anti-tumor necrosis factor and immunomodulator therapy for the treatment of Crohn's disease: a meta-analysis. Clin Gastroenterol Hepatol 2009;7:874881.

19. Wan H. An overall comparison of small molecules and large biologics in ADME testing. ADMET DMPK 2016;4:1-22.

20. Chande N, Patton PH, Tsoulis DJ, Thomas BS, MacDonald JK. Azathioprine or 6-mercaptopurine for maintenance of remission in Crohn's disease. Cochrane Database Syst Rev 2015;(10):CD000067.

21. Timmer A, Patton PH, Chande N, McDonald JW, MacDonald JK. Azathioprine and 6-mercaptopurine for maintenance of remission in ulcerative colitis. Cochrane Database Syst Rev 2016;(5):CD000478.

22. Jovani M, Danese S. Vedolizumab for the treatment of IBD: a selective therapeutic approach targeting pathogenic a4b7 cells. Curr Drug Targets 2013;14:1433-1443.

23. Lobatón T, Vermeire S, Van Assche G, Rutgeerts P. Review ar- ticle: anti-adhesion therapies for inflammatory bowel disease. Aliment Pharmacol Ther 2014;39:579-594.

24. Zundler S, Becker E, Weidinger C, Siegmund B. Anti-adhesion therapies in inflammatory bowel disease-molecular and clinical aspects. Front Immunol 2017;8:891.

25. Sandborn WJ, Colombel JF, Enns R, et al Natalizumab induction and maintenance therapy for Crohn's disease. N Engl J Med 2005;353:1912-1925.

26. Targan SR, Feagan BG, Fedorak RN, et al. Natalizumab for the treatment of active Crohn's disease: results of the ENCORE Trial. Gastroenterology 2007;132:1672-1683.

27. del Pilar Martin M, Cravens PD, Winger R, et al. Decrease in the numbers of dendritic cells and CD4+ T cells in cerebral perivascular spaces due to natalizumab. Arch Neurol 2008;65:1596-1603.

28. Kleinschmidt-DeMasters BK, Tyler KL. Progressive multifocal leukoencephalopathy complicating treatment with natalizumab and interferon beta-1a for multiple sclerosis. N Engl J Med 2005;353:369-374.

29. Langer-Gould A, Atlas SW, Green AJ, Bollen AW, Pelletier D. Progressive multifocal leukoencephalopathy in a patient treated with natalizumab. N Engl J Med 2005;353:375-381.

30. Bloomgren G, Richman S, Hotermans C, et al. Risk of natalizumab-associated progressive multifocal leukoencephalopathy. $\mathrm{N}$ Engl J Med 2012;366:1870-1880.

31. Gordon FH, Hamilton MI, Donoghue S, et al. A pilot study of treatment of active ulcerative colitis with natalizumab, a humanized monoclonal antibody to alpha-4 integrin. Aliment Pharmacol Ther 2002;16:699-705.

32. Feagan BG, Rutgeerts P, Sands BE, et al. Vedolizumab as induction and maintenance therapy for ulcerative colitis. N Engl J Med 2013;369:699-710.

33. Sandborn WJ, Feagan BG, Rutgeerts $P$, et al. Vedolizumab as induction and maintenance therapy for Crohn's disease. N Engl J Med 2013;369:711-721.

34. Sands BE, Feagan BG, Rutgeerts P, et al. Effects of vedolizumab induction therapy for patients with Crohn's disease in whom tumor necrosis factor antagonist treatment failed. Gastroenterology 2014;147:618-627.

35. Feagan BG, Rubin DT, Danese S, et al. Efficacy of vedolizumab induction and maintenance therapy in patients with ulcerative colitis, regardless of prior exposure to tumor necrosis factor antagonists. Clin Gastroenterol Hepatol 2017;15:229-239.

36. Sands BE, Sandborn WJ, Van Assche G, et al. Vedolizumab as induction and maintenance therapy for Crohn's disease in patients naïve to or who have failed tumor necrosis factor antagonist therapy. Inflamm Bowel Dis 2017;23:97-106.

37. Loftus EV Jr, Colombel JF, Feagan BG, et al. Long-term efficacy of vedolizumab for ulcerative colitis. J Crohns Colitis 2017;11:400-411.

38. Vermeire S, Loftus EV Jr, Colombel JF, et al. Long-term efficacy of vedolizumab for Crohn's disease. J Crohns Colitis 2017;11:412424. 
39. Milch C, Wyant T, Xu J, et al. Vedolizumab, a monoclonal antibody to the gut homing alpha4beta7 integrin, does not affect cerebrospinal fluid T-lymphocyte immunophenotype. J Neuroimmunol 2013;264:123-126.

40. Colombel JF, Sands BE, Rutgeerts P, et al. The safety of vedolizumab for ulcerative colitis and Crohn's disease. Gut 2017;66:839-851.

41. Benson JM, Peritt D, Scallon BJ, et al. Discovery and mechanism of ustekinumab: a human monoclonal antibody targeting interleukin-12 and interleukin-23 for treatment of immune-mediated disorders. MAbs 2011;3:535-545.

42. Fuss IJ, Becker C, Yang Z, et al. Both IL-12p70 and IL-23 are synthesized during active Crohn's disease and are down-regulated by treatment with anti-IL-12 p40 monoclonal antibody. Inflamm Bowel Dis 2006;12:9-15.

43. Wittig BM. Drug evaluation: CNTO-1275, a mAb against IL-12/ IL-23p40 for the potential treatment of inflammatory diseases. Curr Opin Investig Drugs 2007;8:947-954.

44. Feagan BG, Sandborn WJ, Gasink C, et al. Ustekinumab as induction and maintenance therapy for Crohn's disease. N Engl J Med 2016;375:1946-1960.

45. Hibi T, Imai Y, Murata Y, Matsushima N, Zheng R, Gasink C. Efficacy and safety of ustekinumab in Japanese patients with moderately to severely active Crohn's disease: a subpopulation analysis of phase 3 induction and maintenance studies. Intest Res 2017;15:475-486.

46. Sandborn WJ, Rutgeerts P, Gasink C, et al. Long-term efficacy and safety of ustekinumab for Crohn's disease through the second year of therapy. Aliment Pharmacol Ther 2018;48:65-77.

47. Papp KA, Griffiths CE, Gordon K, et al. Long-term safety of ustekinumab in patients with moderate-to-severe psoriasis: final results from 5 years of follow-up. Br J Dermatol 2013;168:844854.

48. Menter A, Papp KA, Gooderham M, et al. Drug survival of biologic therapy in a large, disease-based registry of patients with psoriasis: results from the Psoriasis Longitudinal Assessment and Registry (PSOLAR). J Eur Acad Dermatol Venereol 2016;30:11481158.

49. Papp K, Gottlieb AB, Naldi L, et al. Safety surveillance for ustekinumab and other psoriasis treatments from the Psoriasis Longitudinal Assessment and Registry (PSOLAR). J Drugs Dermatol 2015;14:706-714.

50. Shuai K, Liu B. Regulation of JAK-STAT signalling in the immune system. Nat Rev Immunol 2003;3:900-911.

51. Murray PJ. The JAK-STAT signaling pathway: input and output integration. J Immunol 2007;178:2623-2629.

52. Ghoreschi K, Laurence A, O'Shea JJ. Janus kinases in immune cell signaling. Immunol Rev 2009;228:273-287.

53. Olivera P, Danese S, Peyrin-Biroulet L. Next generation of small molecules in inflammatory bowel disease. Gut 2017;66:199-209.

54. Sandborn WJ, Su C, Sands BE, et al. Tofacitinib as induction and maintenance therapy for ulcerative colitis. N Engl J Med
2017;376:1723-1736.

55. Sandborn WJ, Panés J, D’Haens GR, et al. Safety of tofacitinib for treatment of ulcerative colitis, based on 4.4 years of data from global clinical trials. Clin Gastroenterol Hepatol 2019;17:15411550.

56. Charles-Schoeman C, Wicker P, Gonzalez-Gay MA, et al. Cardiovascular safety findings in patients with rheumatoid arthritis treated with tofacitinib, an oral Janus kinase inhibitor. Semin Arthritis Rheum 2016;46:261-271.

57. Sandborn WJ, Ghosh S, Panes J, et al. A phase 2 study of tofacitinib, an oral Janus kinase inhibitor, in patients with Crohn's disease. Clin Gastroenterol Hepatol 2014;12:1485-1493.

58. Panés J, Sandborn WJ, Schreiber S, et al. Tofacitinib for induction and maintenance therapy of Crohn's disease: results of two phase Ilb randomized placebo-controlled trials. Gut 2017;66:1049-1059.

59. Tang MT, Keir ME, Erickson R, et al. Review article: nonclinical and clinical pharmacology, pharmacokinetics and pharmacodynamics of etrolizumab, an anti-beta7 integrin therapy for inflammatory bowel disease. Aliment Pharmacol Ther 2018;47:14401452.

60. Cepek KL, Parker CM, Madara JL, Brenner MB. Integrin alpha E beta 7 mediates adhesion of T lymphocytes to epithelial cells. J Immunol 1993;150(8 Pt 1):3459-3470.

61. Vermeire S, O’Byrne S, Keir M, et al. Etrolizumab as induction therapy for ulcerative colitis: a randomised, controlled, phase 2 trial. Lancet 2014;384:309-318.

62. Selinger C, Sandborn W, Panes J, et al. OTU-003 Etrolizumab as induction therapy in moderate to severe Crohn's disease: results from bergamot cohort 1. Gut 2018;67 (Suppl 1):A53-A53.

63. Vermeire S, Ghosh S, Panes J, et al. The mucosal addressin cell adhesion molecule antibody PF-00547,659 in ulcerative colitis: a randomised study. Gut 2011;60:1068-1075.

64. Vermeire S, Sandborn WJ, Danese S, et al. Anti-MAdCAM antibody (PF-00547659) for ulcerative colitis (TURANDOT): a phase 2, randomised, double-blind, placebo-controlled trial. Lancet 2017;390:135-144.

65. Sandborn WJ, Lee SD, Tarabar D, et al. Phase II evaluation of anti-MAdCAM antibody PF-00547659 in the treatment of Crohn's disease: report of the OPERA study. Gut 2018;67:1824-1835.

66. Feagan BG, Sandborn WJ, D’Haens G, et al. Induction therapy with the selective interleukin-23 inhibitor risankizumab in patients with moderate-to-severe Crohn's disease: a randomised, double-blind, placebo-controlled phase 2 study. Lancet 2017;389:1699-1709.

67. Feagan BG, Panés J, Ferrante M, et al. Risankizumab in patients with moderate to severe Crohn's disease: an open-label extension study. Lancet Gastroenterol Hepatol 2018;3:671-680.

68. Sands BE, Chen J, Feagan BG, et al. Efficacy and safety of MEDI2070, an antibody against interleukin 23, in patients with moderate to severe Crohn's disease: a phase 2a study. Gastroenterology 2017;153:77-86.

69. Mannon PJ, Fuss IJ, Mayer L, et al. Anti-interleukin-12 antibody 
for active Crohn's disease. N Engl J Med 2004;351:2069-2079.

70. Panaccione R, Sandborn WJ, Gordon GL, et al. Briakinumab for treatment of Crohn's disease: results of a randomized trial. Inflamm Bowel Dis 2015;21:1329-1340.

71. Vermeire S, Schreiber S, Petryka R, et al. Clinical remission in patients with moderate-to-severe Crohn's disease treated with filgotinib (the FITZROY study): results from a phase 2, doubleblind, randomised, placebo-controlled trial. Lancet 2017;389:266275.

72. Sandborn WJ, Feagan BG, Panes J, et al. Safety and efficacy of ABT-494 (upadacitinib), an oral Jak1 inhibitor, as induction therapy in patients with Crohn's disease: results from Celest. Gastroenterology 2017;152:S1308-S1309.

73. Marafini I, Zorzi F, Codazza S, Pallone F, Monteleone G. TGFbeta signaling manipulation as potential therapy for IBD. Curr Drug Targets 2013;14:1400-1404.

74. Monteleone G, Kumberova A, Croft NM, McKenzie C, Steer HW, MacDonald TT. Blocking Smad7 restores TGF-beta1 signaling in chronic inflammatory bowel disease. J Clin Invest 2001;108:601609.

75. Boirivant M, Pallone F, Di Giacinto C, et al. Inhibition of Smad7 with a specific antisense oligonucleotide facilitates TGF-beta1mediated suppression of colitis. Gastroenterology 2006;131:17861798.

76. Monteleone G, Neurath MF, Ardizzone S, et al. Mongersen, an oral SMAD7 antisense oligonucleotide, and Crohn's disease. N Engl J Med 2015;372:1104-1113.

77. Spadaccini M, D’Alessio S, Peyrin-Biroulet L, Danese S. PDE4 inhibition and inflammatory bowel disease: a novel therapeutic avenue. Int J Mol Sci 2017;18:E1276.

78. Danese S, Neurath M, Kopon A, et al. OP006 Apremilast for active ulcerative colitis: a phase 2 , randomised, double-blind, placebo-controlled induction study. J Crohns Colitis 2018;12(Suppl 1):S004.

79. Sanchez T, Hla T. Structural and functional characteristics of S1P receptors. J Cell Biochem 2004;92:913-922.

80. Peyrin-Biroulet L, Christopher R, Behan D, Lassen C. Modulation of sphingosine-1-phosphate in inflammatory bowel disease. $\mathrm{Au}$ toimmun Rev 2017;16:495-503.

81. Mullershausen F, Zecri F, Cetin C, Billich A, Guerini D, Seuwen K. Persistent signaling induced by FTY720-phosphate is mediated by internalized S1P1 receptors. Nat Chem Biol 2009;5:428-434.

82. O'Sullivan C, Dev KK. The structure and function of the S1P1 receptor. Trends Pharmacol Sci 2013;34:401-412.

83. Scott FL, Clemons B, Brooks J, et al. Ozanimod (RPC1063) is a potent sphingosine-1-phosphate receptor-1 (S1P1) and receptor-5 (S1P5) agonist with autoimmune disease-modifying activity. Br J Pharmacol 2016;173:1778-1792.

84. Sandborn WJ, Feagan BG, Wolf DC, et al. Ozanimod induction and maintenance treatment for ulcerative colitis. N Engl J Med
2016;374:1754-1762.

85. Posters of distinction P-001 to P-018. Am J Gastroenterol 2018;113:S1-S5.

86. Inflammatory bowel disease (abstracts 568-744). Am J Gastroenterol. Epub 2018 Oct 25. https://doi.org/10.1038/s41395-0180296-0.

87. Colombel JF, Sandborn WJ, Reinisch W, et al. Infliximab, azathioprine, or combination therapy for Crohn's disease. N Engl J Med 2010;362:1383-1395.

88. Panaccione R, Ghosh S, Middleton S, et al. Combination therapy with infliximab and azathioprine is superior to monotherapy with either agent in ulcerative colitis. Gastroenterology 2014;146:392400.

89. Matsumoto T, Motoya S, Watanabe K, et al. Adalimumab monotherapy and a combination with azathioprine for Crohn's disease: a prospective, randomized trial. J Crohns Colitis 2016;10:12591266.

90. Sands BE, Kozarek R, Spainhour J, et al. Safety and tolerability of concurrent natalizumab treatment for patients with Crohn's disease not in remission while receiving infliximab. Inflamm Bowel Dis 2007;13:2-11.

91. Hirten RP, Iacucci M, Shah S, Ghosh S, Colombel JF. Combining biologics in inflammatory bowel disease and other immune mediated inflammatory disorders. Clin Gastroenterol Hepatol 2018;16:1374-1384.

92. van Nood E, Vrieze A, Nieuwdorp M, et al. Duodenal infusion of donor feces for recurrent Clostridium difficile. N Engl J Med 2013;368:407-415.

93. Surawicz CM, Brandt LJ, Binion DG, et al. Guidelines for diagnosis, treatment, and prevention of Clostridium difficile infections. Am J Gastroenterol 2013;108:478-498.

94. Bennet JD, Brinkman M. Treatment of ulcerative colitis by implantation of normal colonic flora. Lancet 1989;1:164.

95. Paramsothy S, Paramsothy R, Rubin DT, et al. Faecal microbiota transplantation for inflammatory bowel disease: a systematic review and meta-analysis. J Crohns Colitis 2017;11:1180-1199.

96. Narula N, Kassam Z, Yuan Y, et al. Systematic review and metaanalysis: fecal microbiota transplantation for treatment of active ulcerative colitis. Inflamm Bowel Dis 2017;23:1702-1709.

97. Na SY, Moon W. Evolving therapeutic strategies in the inflammatory bowel disease. Korean J Gastroenterol 2018;71:61-68.

98. Okamoto R, Watanabe M. Investigating cell therapy for inflammatory bowel disease. Expert Opin Biol Ther 2016;16:1015-1023.

99. Hawkey CJ, Allez M, Clark MM, et al. Autologous hematopoetic stem cell transplantation for refractory Crohn disease: a randomized clinical trial. JAMA 2015;314:2524-2534.

100. Panés J, García-Olmo D, Van Assche G, et al. Expanded allogeneic adipose-derived mesenchymal stem cells (Cx601) for complex perianal fistulas in Crohn's disease: a phase 3 randomised, double-blind controlled trial. Lancet 2016;388:1281-1290. 